\title{
Formation of parasitic nodules in the swimbladder and intestinal walls of the eel Anguilla anguilla due to infections with larval stages of Anguillicola crassus
}

\author{
K. Molnár \\ Veterinary Medical Research Institute, Hungarian Academy of Sciences, PO Box 18, H-1581 Budapest, Hungary
}

\begin{abstract}
The histopathological lesions caused by 3rd and 4th stage migrating larvae of Anguillicola crassus in the swimbladder and intestinal wall of eel were studied. Some of the larvae were detectable in the oedematous connective tissue of the swimbladder subserosa and in the gas gland without giving rise to a significant cellular host reaction. In some eel, tissue proliferation consisting of epithelioid cells started around the migrating larvae. In more advanced cases, the epithelioid cells around the larvae underwent necrosis in the deep layers of the granulation tissue, giant cells were formed, and the nodule became surrounded by a fibrous capsule. In more chronic cases the nodules contained necrotic larvae and amorphous cell debris. In the case of an enteric infection, a similar nodule formation was observed in the intestine. The parasitic nodules bulging out the serosa of the intestinal wall towards the abdominal cavity occasionally changed into abscesses (pustules). In anguillicolosis, cysts lined with epithelium and filled with serum also commonly occur in the swimbladder mucosa; however, these could not be brought into connection with larval migration.
\end{abstract}

KEY WORDS: Histopathology Anguillicola crassus Eel - Larval stages - Nodules Pustules

\section{INTRODUCTION}

Numerous papers have addressed the European spread and development of Anguillicola crassus (Nematoda: Dracunculoidea) and the dynamics of the parasitosis caused by it. At the same time, few reports have dealt with the pathology of anguillicolosis, and even less have been concerned with its histopathological aspects. To the latter belongs the paper of van Banning \& Haenen (1990) who gave a short description of the histopathological changes caused by adults and larvae of $A$. crassus in the swimbladder of eel. Haenen et al. (1989) described the effect exerted by migrating larvae on the swimbladder wall on the basis of infection experiments.

Following the massive eel mortality that took place in Lake Balaton, Hungary, in 1991 and 1992 (Molnár et al. 1991), detailed studies were started in Hungary on the pathology (Csaba et al. 1993, Molnár et al. 1993) and dynamics (Molnár et al. 1994) of anguillicolosis, the lesions caused by abnormally located adults and 2nd stage larvae (Molnár et al. 1995), the correlation between anguillicolosis and water oxygen content (Molnár 1993), and the prevalence of Anguillicola crassus larvae in paratenic hosts (Székely 1993). The histopathological lesions caused by migrating larvae were only briefly mentioned in these papers even though Molnár et al. (1993) incriminated immunological response by the fish to repeated larval infection as the main factor responsible for the swimbladder lesions developing in $A$. crassus infection.

The histopathological changes caused by migrating 3rd and 4th stage Anguillicola crassus larvae in the wall of the swimbladder and intestine are described in the present paper.

\section{MATERIALS AND METHODS}

The test material comprised histological sections prepared from several hundred eels during our work aimed at surveying the anguillicolosis of eels in Lake 


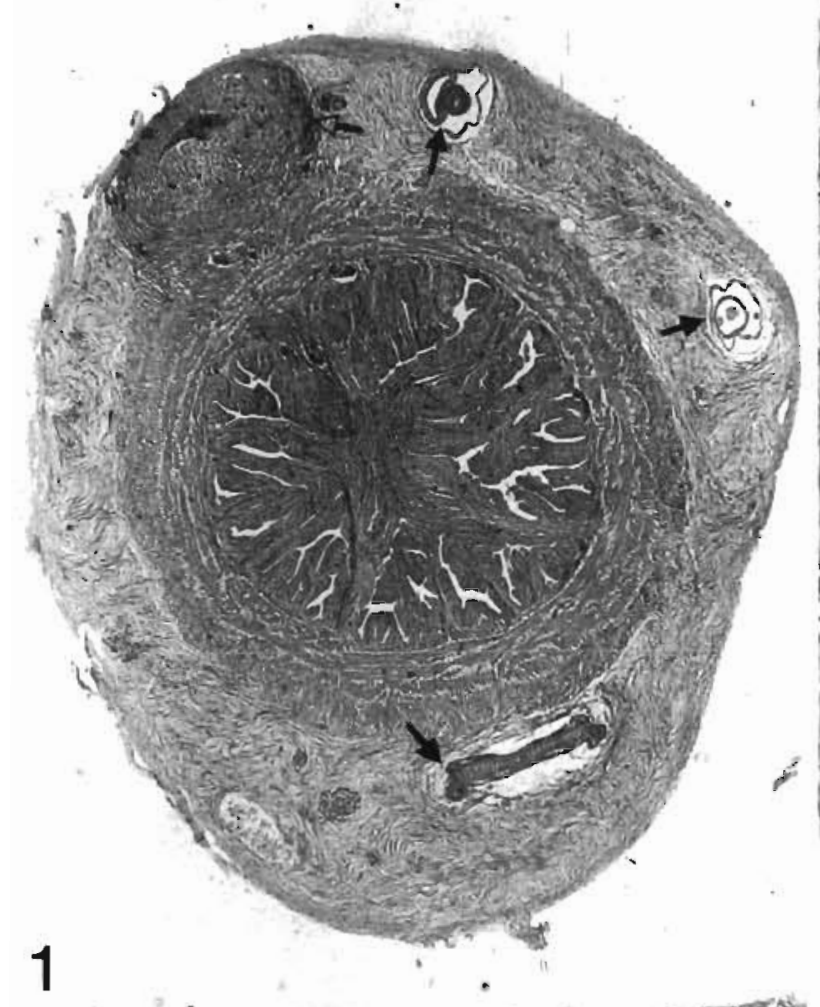

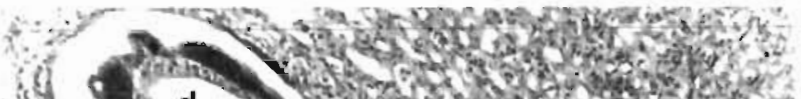

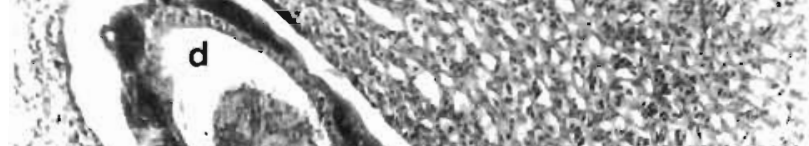

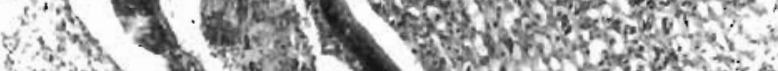

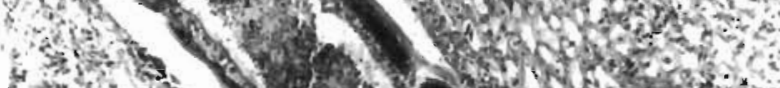

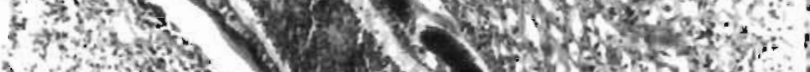

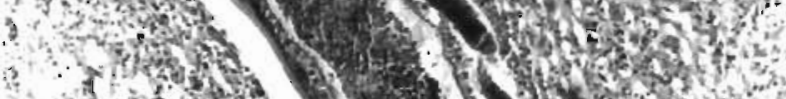

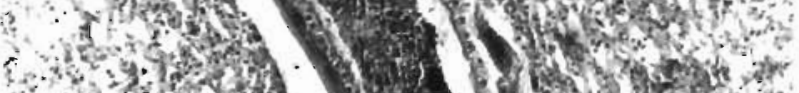

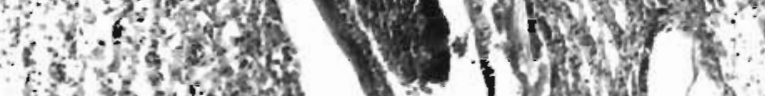

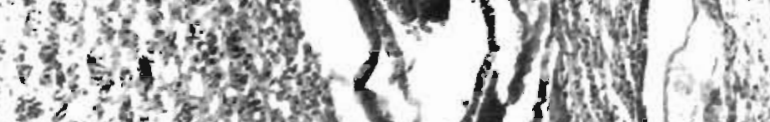

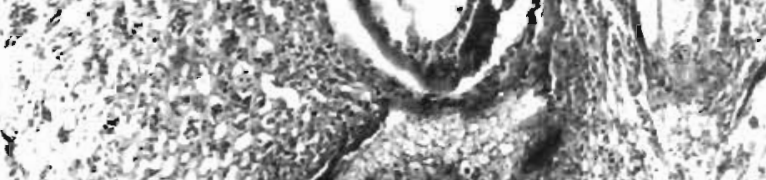

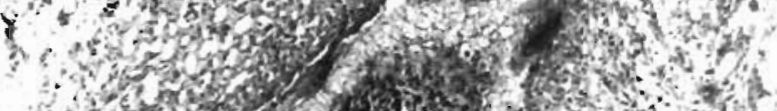

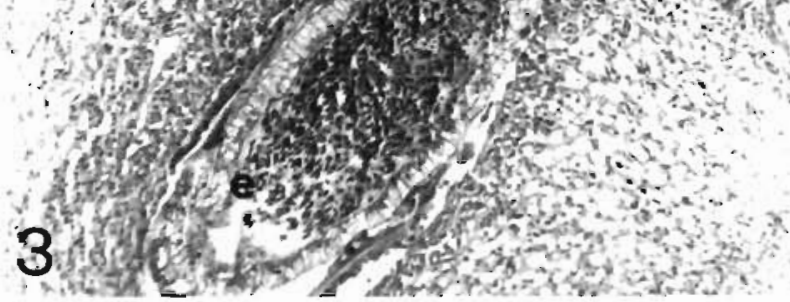

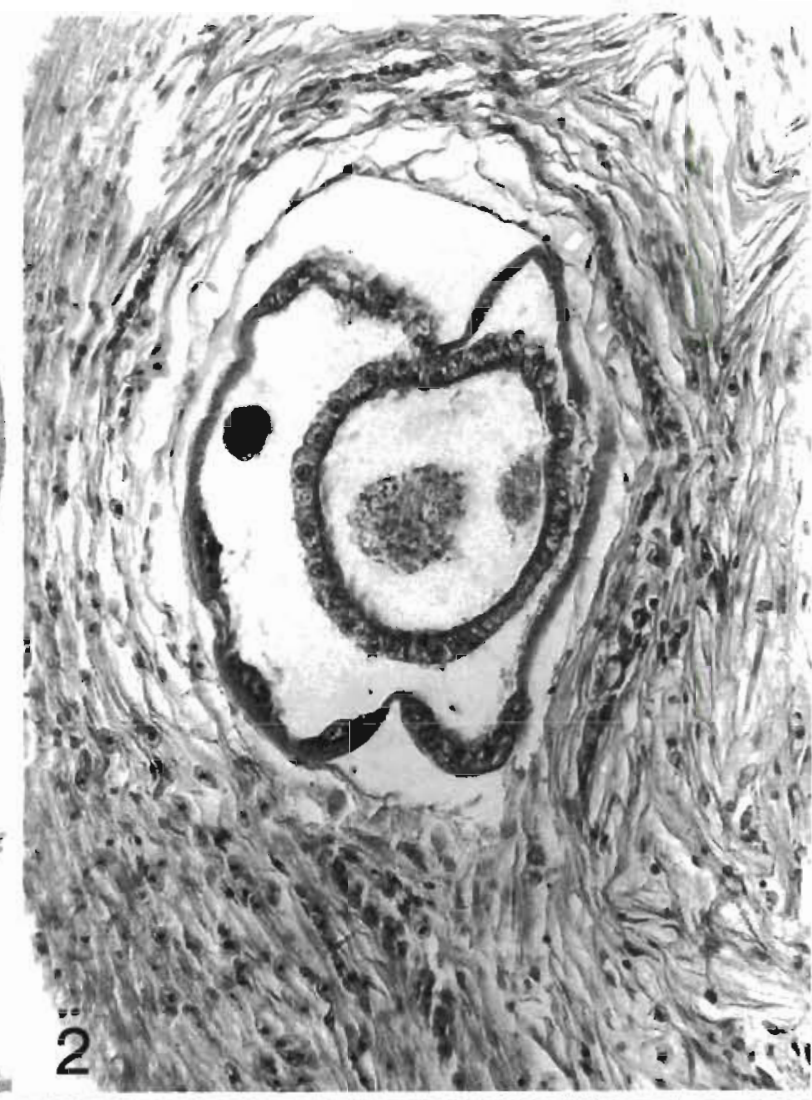

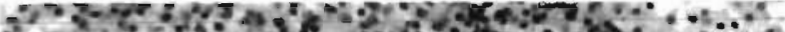

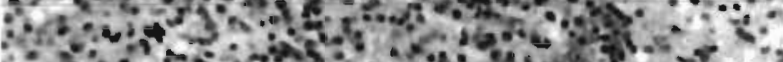

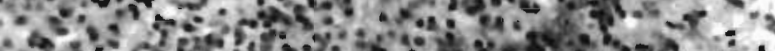

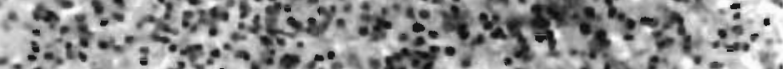

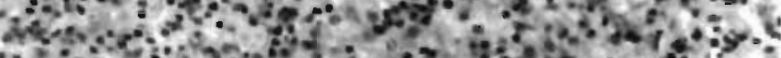

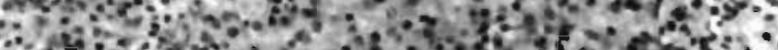

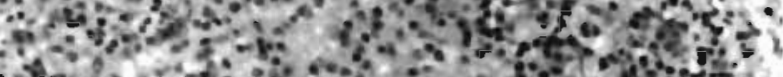

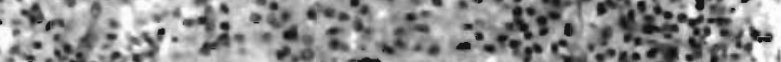
1.

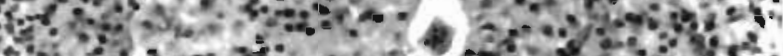

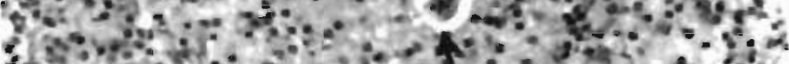

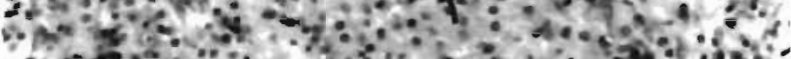

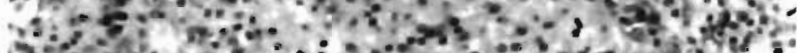

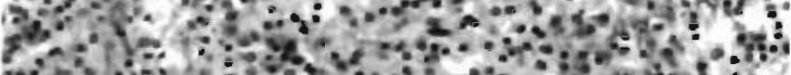

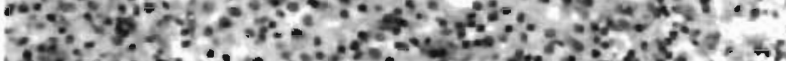

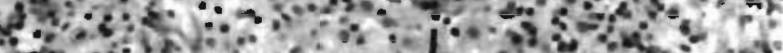
An.

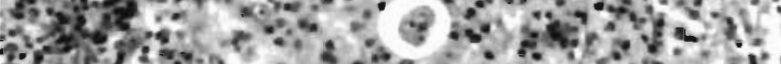
3 r.

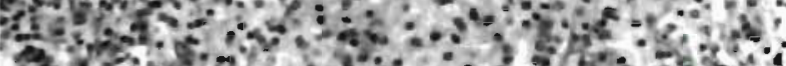

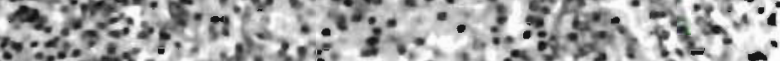

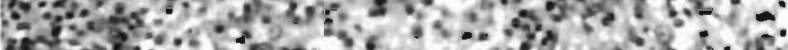

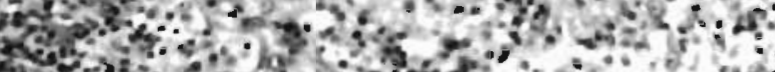

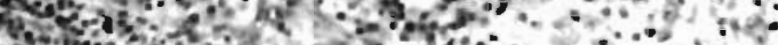

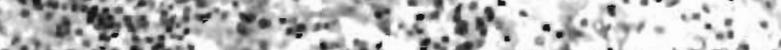

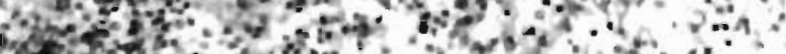

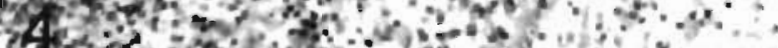

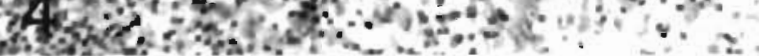


Balaton (see Molnár et al. 1993, 1994, 1995). During the eel dissections performed between August 1991 and December 1993, organs of eels showing characteristic tissue changes were fixed in Bouin's solution or $10 \%$ formalin. After embedding the blocks in paraffin wax, $4 \mu \mathrm{m}$ thick sections were prepared from them and stained with haematoxylin and eosin

\section{RESULTS}

Based upon examination of histological sections prepared from natural cases, infection by Anguillicola crassus larvae showed a rather diverse picture. Some fish exhibited a pronounced inflammatory response, while in other cases larval migration was not followed by a significant cellular response, and the regressive changes were accompanied only by serous infiltration of the larva-containing tunica externa of the swimbladder and by minor haemorrhages. It was a common finding (Fig. 1) that in the same swimbladder wall some larvae elicited an intense host reaction while others were present in tissues undisturbed by any cellular host response except for oedema of loose connective tissue (Fig. 2). Occasionally a similar process was observed in the rete mirabile of the gas glands where the 4 th stage larvae, already feeding on blood, caused only tissue lesions (Fig. 3).

The first sign of tissue reaction was the appearance, then aggregation, of epithelioid macrophages around the larvae. Granulation tissue consisting of such epithelioid cells was formed around both the 3rd and the 4 th stage larvae. The tissue, which consisted of numerous epithelioid cells and round cells (probably macrophages), restricted the movement of the larvae which, however, maintained their viability (Fig. 4). The epithelioid cells located in the outer layers around certain larvae gradually became elongated, assumed a fibroblast character, and formed a capsule (Fig. 5). In such capsules, first the inside epithelioid cell layer and then the larvae themselves became degenerate. Subsequently (Figs. $6 \&$ 7), inside the compact fibrous layer formed around the larva, the necrotized epithelioid cells gave rise to an amorphous tissue debris in which the outlines of the necrotic larva were still discernible. The capsule bordered by compact connective tissue was surrounded from the outside by another layer of looser connective tissue. In more chronic cases, the remnants of the larva were hardly discernible in the necrotic substance within the fibrous capsule (Fig 8). Larval necrosis occasionally took place before the formation of a fibrous capsule. In such cases the innermost layer of the thick epithelioid cell mass formed around the larva already consisted of necrotic cells (Fig. 9), while the surrounding and also damaged cell layer contained both foreign-body-type and Langhans-type giant cells (Figs. $10 \& 11$ ). In severe infection, serum-filled cysts appeared in the tunica propria of the swimbladder wall (Fig. 12). These cysts (Fig. 13) were lined with epithelium and the serum filling their cavity contained pycnotic, rounded cells. Severe swimbladder lesions may be accompanied by the appearance of nodules containing live or dead larvae also in the intestinal wall. Because of these nodules, long segments of affected intestine assumed a tuberculated (nodular) appearance.

The structure of these nodules was identical with those observed in the swimbladder. The nodules were usually located in the external layer of the intestinal wall, mostly under the serosa (Fig. 14). Occasionally these nodules were replaced by cysts filled with pus (Fig. 14), while in a few cases the nodules still contained a live larva embedded in granulation tissue, without abscess formation (Fig. 14). In other cases the serosa became separated from the granule formed around the helminth, and the space between the 2 layers was filled with serous exudate (Fig. 15).

\section{DISCUSSION}

The location of Anguillicola crassus larvae in the swimbladder wall of eels and the diverse host reaction elicited by the larvae are characteristic manifestations of the relationship between the eel and its parasite. The presence of $3 \mathrm{rd}$ and 4 th stage larvae in the subserosa and in the enlarged gas glands without a host reaction in a certain number of cases indicates a high degree of adaptation of the parasite to Anguilla species. Obviously, such larvae successfully complete their developmental cycle in those locations and then migrate into the swimbladder lumen where they reach

Figs. 1 to 4. Anguillicola crassus infecting Anguilla anguilla. Fig. 1. Eel swimbladder with collapsed lumen and thickened wall. Note 4th stage A. crassus larvae (solid arrows) in the loose connective tissue of the subserosa and a nodule that developed around a 3rd stage larva (open arrow). Haematoxylin and eosin (H\&E), $\times 30$. Fig. 2. Cross-section of a 4th stage A. crassus larva located in the swimbladder wall subserosa showing serous infiltration. H\&E, $\times 230$. Fig. 3. Haematophagous 4 th stage $A$. crassus larva in the rete mirabile of the swimbladder. No cellular host reaction can be observed around the larva. One segment of its gut contains erythrocytes (e) while another contains digested, amorphous cell debris (d). H\&E, $\times 100$. Fig. 4. Still viable 3rd stage A. crassus larvae (arrows) isolated by epithelioid macrophages in the swimbladder wall. $\mathrm{H} \& \mathrm{E}, \times 300$ 
and

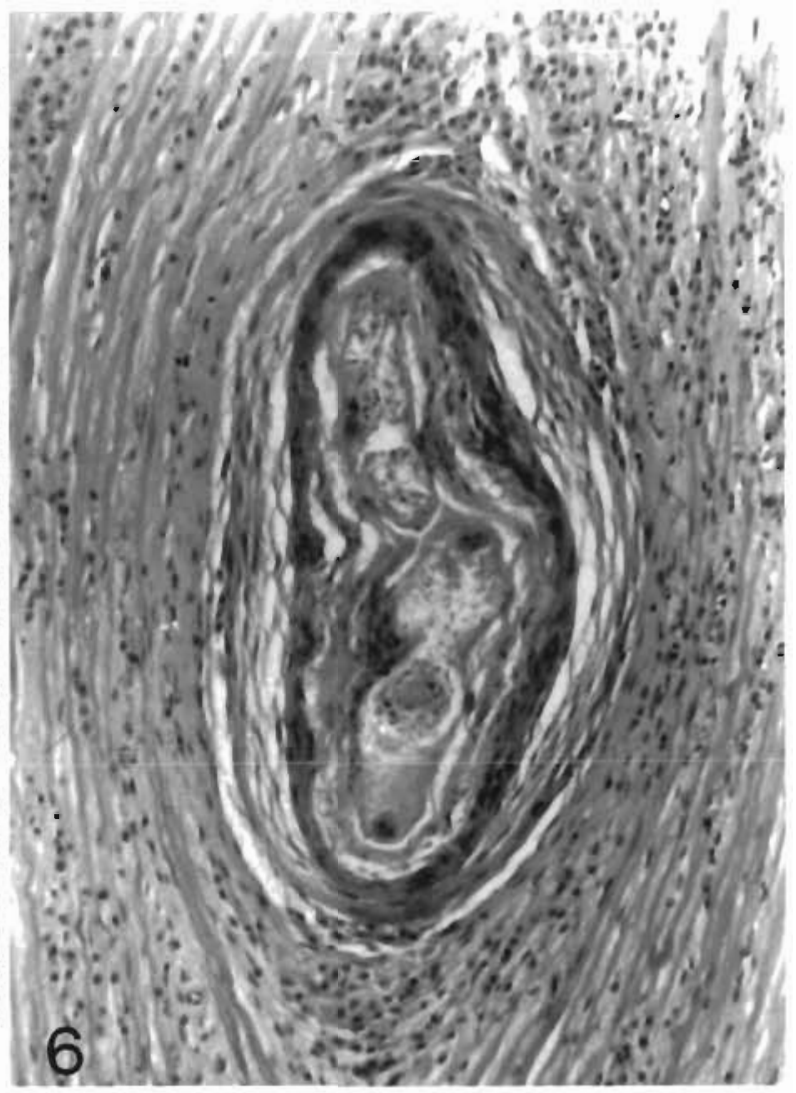

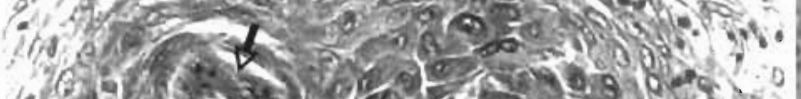
2. (Q) M 15.

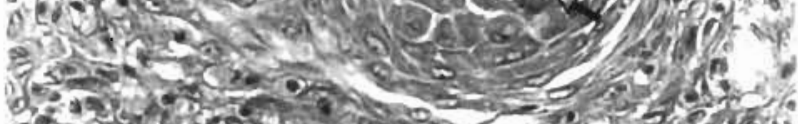

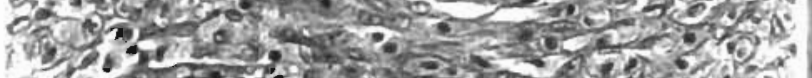

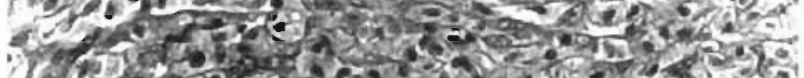

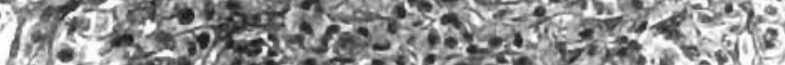

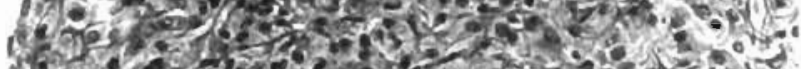
Then a a

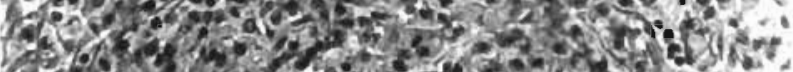

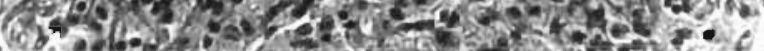
sila

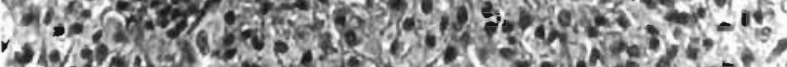
$r$ - 1 .

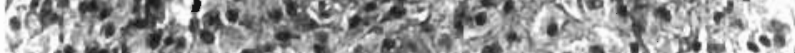
13.

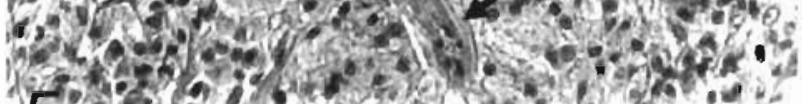

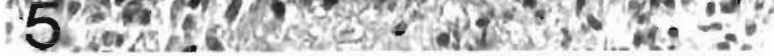
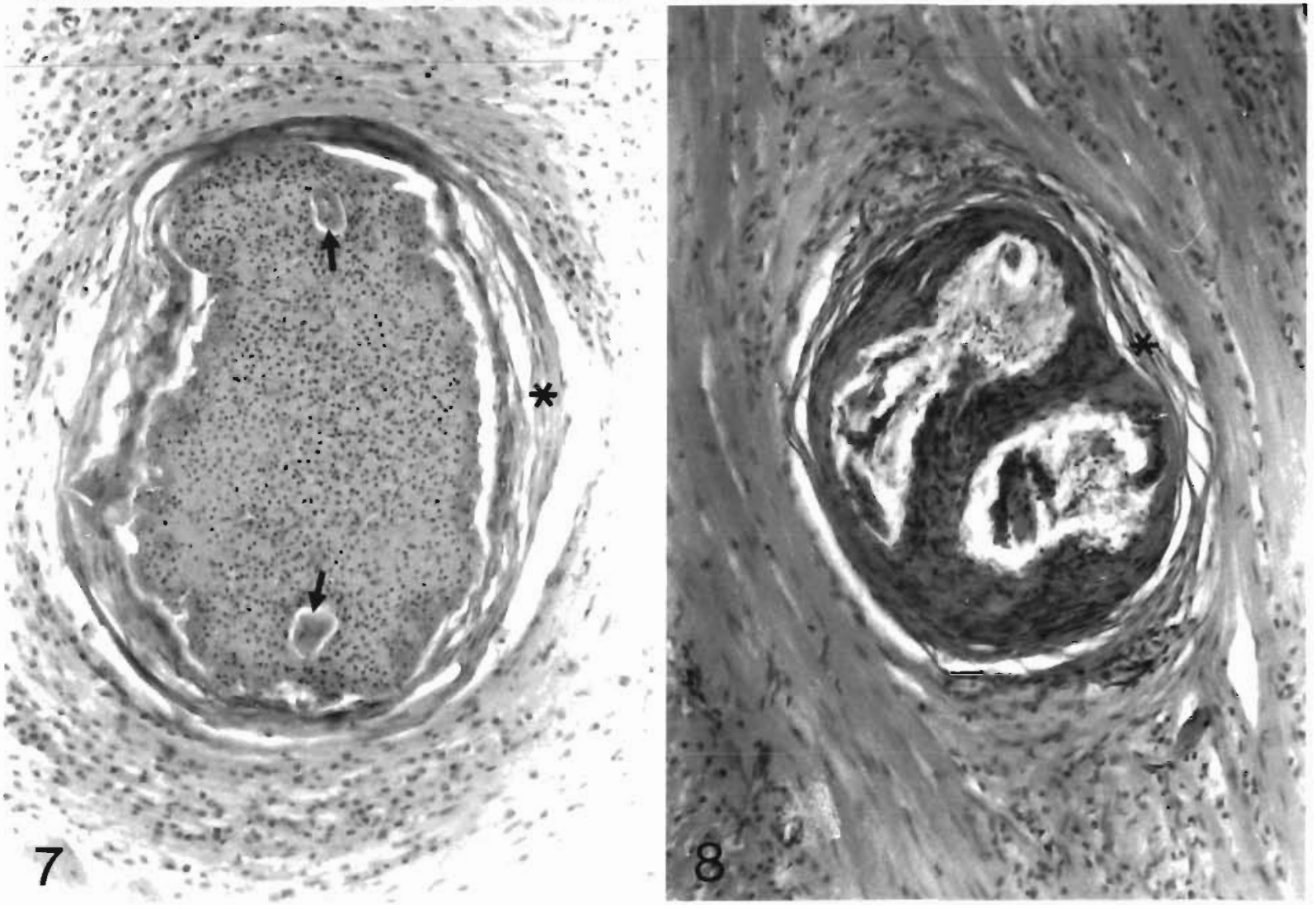
Figs. 5 to 8. Anguillicola crassus infecting Anguilla anguilla. Fig. 5. 3rd stage A. crassus larvae (solid arrow) surrounded by epithelioid cells and enclosed by degenerate epithelioid cells and a thin connective tissue capsule (open arrows) in the swimbladder wall. H\&E, $\times 360$. Fig. 6 . A crassus larva destroyed by cellular reaction. An amorphous substance, consisting of necrotic epithelioid cells, adheres to the surface of the larva. This is surrounded by a compact then a looser connective tissue layer. H\&E. $\times 300$. Fig. 7. Cross-sections of a 3 rd stage $A$. crassus larva (arrows) isolated by a multilayered connective tissue capsule ( $*$ ). The larva is surrounded by amorphous cell debris. $\mathrm{H} \& \mathrm{E}, \times 300$. Fig. 8 . A nodule containing a dead $A$. crassus larva in the intestinal wall. The split-up live connective tissue $(*)$ contains necrotic connective tıssue, amorphous cellular material, and larval residues $\mathrm{H} \& \mathrm{E}, \times 23$

maturity. At the same time, the large number of dead larvae, or those with restricted motility, found in the swimbladder wall suggests that parasite adaptation is successful to a certain limit only and, possibly as a result of repeated invasions, the host's defence mechanism becomes activated and destroys the larvae. The oedematous infiltration of the subserosa, elicited by larval infection, does not seem to inhibit larval development; however, the epithelioid macrophages accumulating around the larvae constitute the first step in the restriction of larval migration. Thickening of the epithelioid layer, then gradual elongation of the external epithelioid cells and the formation of the connec- tive tissue capsule result in degeneration of the epithelioid cells located at the centre of the nodule. This will lead to the formation of giant cells and then to full necrosis of the cells surrounding the parasite. Besides phagocytic activity and the effect of cytokines, probably the impaired feeding possibilities due to necrosis of the host cells cause the death of the surrounded larva. As the presence of larval nodules is much less common in the intestine than in the swimbladder, such nodules are likely to be formed only after infection by very large numbers of larvae and upon repeated invasion.

In the intestine, the host reaction seems to appear only after full immunological conversion of the organ-
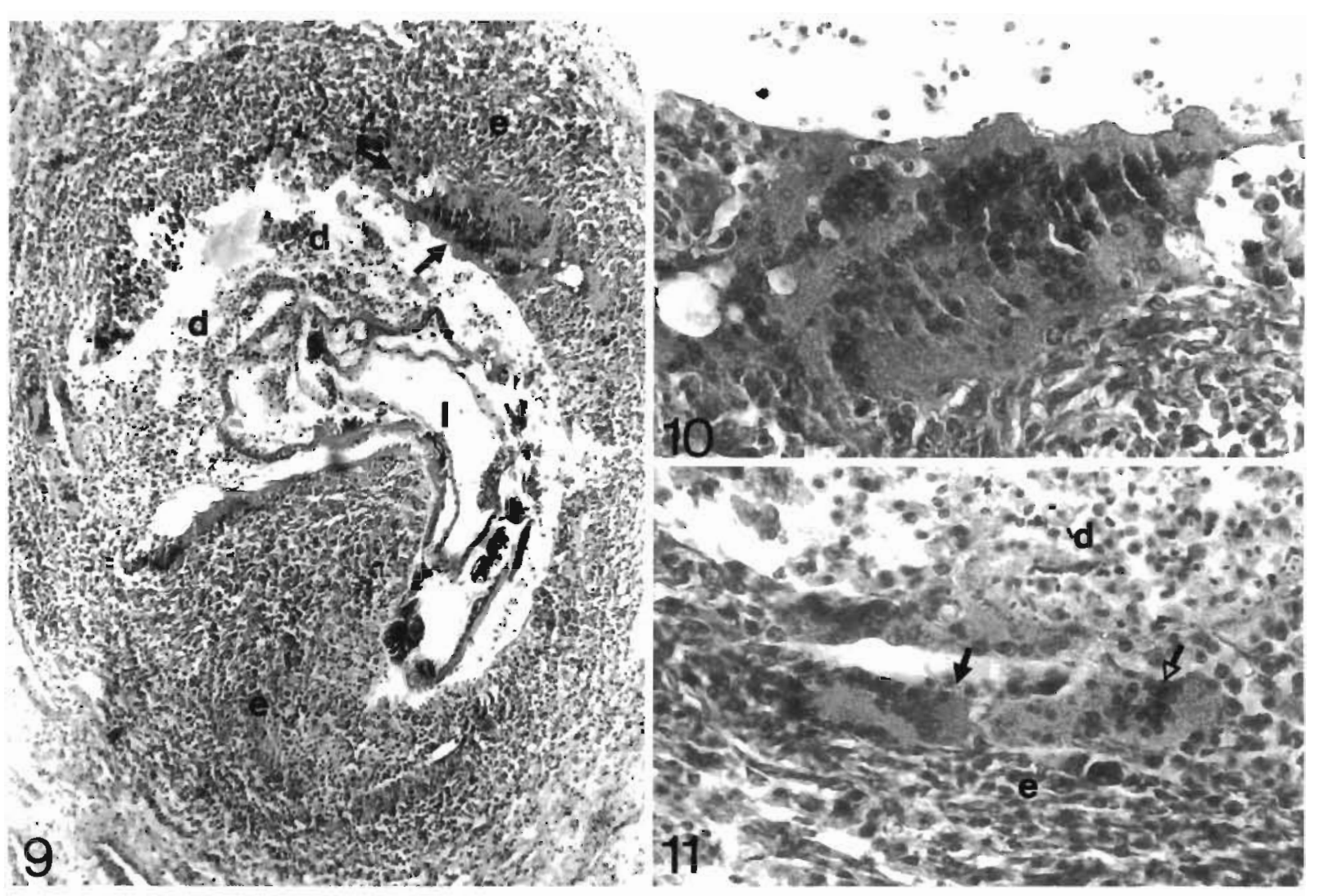

Figs. 9 to 11. Anguillicola crassus infecting Anguilla anguilla. Fig. 9. 4th stage A. crassus larva (l) surrounded by granulation tissue consisting of epithelioid cells (e), necrotic epithelioid cells (d) and giant cells (arrows) in the swimbladder wall of eel. H\&E, $\times$ 120. Fig. 10. Magnified detail of Fig. 9. Foreign-body-type giant cell in part of the granulation tissue adjacent to the larva. H\&E, $\times 400$. Fig. 11. Detail of Fig. 9. Note Langhans-type (solid arrow) and foreign-body-type (open arrow) giant cells among the dead (d) and still-living epithelioid cells (e). H\&E, $\times 400$ 

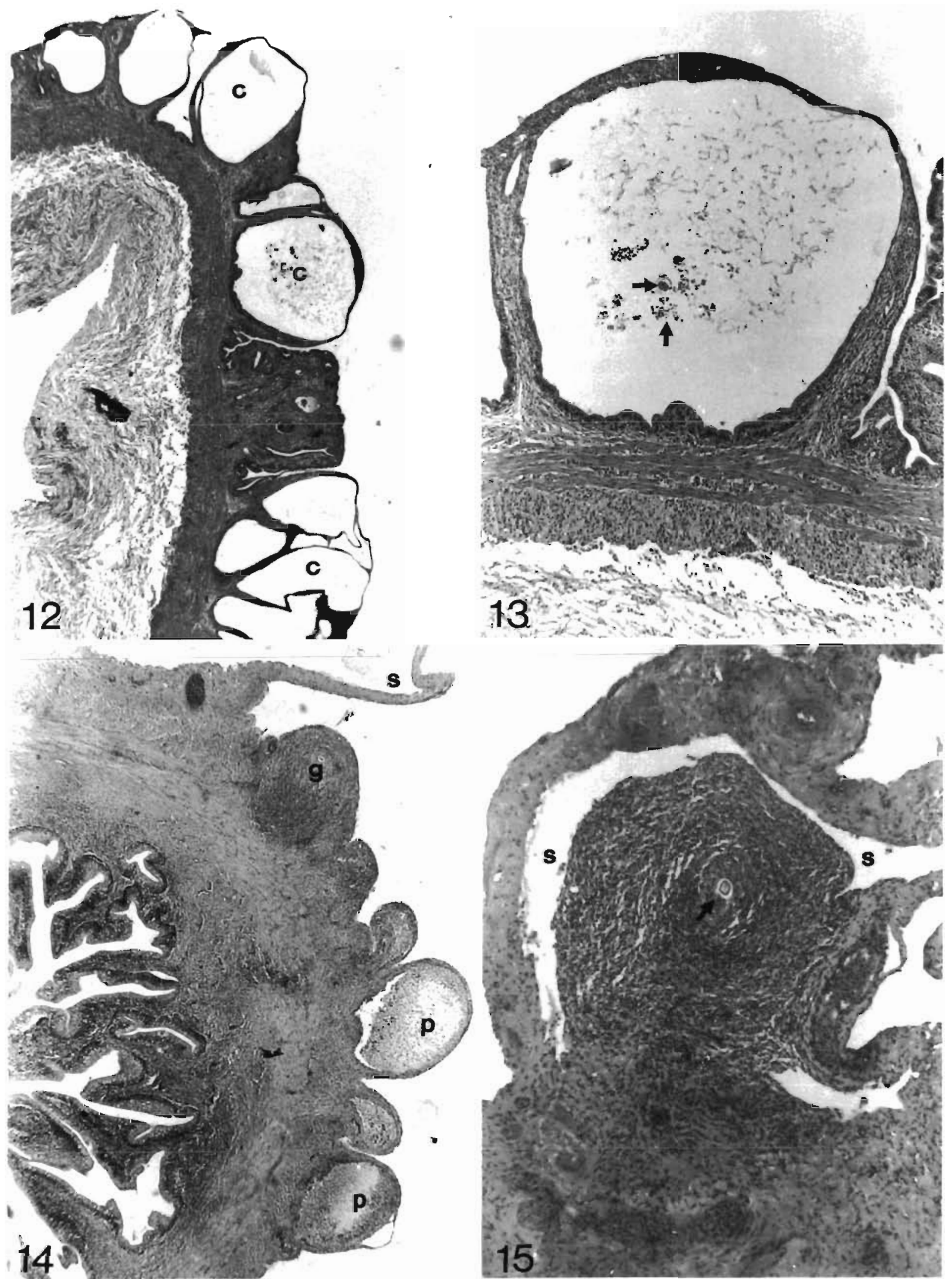
ism. The parasitic nodules and the type of host reaction observed in the intestine are practically identical to those seen in the swimbladder and, as in the swimbladder, these changes are restricted to the subserosa. At the same time, it is difficult to explain why the granulation tissue developing under the serosa and bulging out towards the abdominal cavity separates from the serosa, and how a serous cyst is formed between the 2 layers, a cyst which then, presumably through the action of bacteria arriving from the intestine, changes into a purulent cyst visible with the unaided eye. Probably there is only an analogy between the cysts found on the intestinal serosa and those formed in the tunica propria of the swimbladder. The origin of cysts formed on the serosa and of those evolving in the tunica propria seems to be different. While the former were always associated with larval development, no larval activity was observed in cysts formed in the tunica propria of the swimbladder. The latter may instead be due to oedema, which is considered to be a general sign of anguillicolosis. However, this seems to be contradicted by the finding that the lumen of the cysts is lined by epithelial cells. At the same time, the possibility cannot be excluded that the presence of cysts was due to the pathogenic effect of adults feeding in the lumen, rather than to the larvae.

Presumably no host reaction is mounted against the first migrating larvae which easily get into the swimbladder lumen on completing their development. At the same time, it is obvious that a successful cellular host response develops after a certain time against repeatedly invading larvae or, in the case of a highly intensive infection, against the less viable larvae. This host reaction results in the encapsulation and subsequent destruction of the larvae. In the majority of cases such a response occurs only in the swimbladder, while in more severe infections it also develops in the intestine.

According to Molnár et al. (1994), the prevalence of live larval infection of the swimbladder of Lake Balaton eels varies between 25 and $60 \%$, and shows no distinct seasonal variation. These data, together with the present results, indicate that Anguillicola crassus infection is continuous and occurs from year to year. As no seasonality is demonstrable, one must assume that different eel specimens reach the level of infectioninduced immunity necessary for elimination of the adult nematodes and destruction of the larvae at a different time. At the same time, it is also obvious that the resistance to reinfection of fish is not infinite, and the elimination of larvae will inevitably be followed by a stage when reinfection elicits no major host response, i.e. tolerance will ensue.

The host response developing to nematode larvae migrating in mammals was reviewed in detail by Poynter (1966) and Frenkel et al. (1988). They described the host response to the migrating larvae of some nematodes parasitic in the lungs, blood, body tissues and intestine to be primarily one of encapsulation. The authors cited in these reviews regarded oedema, haemorrhages and inflammatory cellular infiltration of the tissues as the first sign of invasion by parasite larvae. This was followed by granuloma formation with the participation of fibroblasts, epithelioid cells and giant cells; however, the process was consistently characterized by the presence of eosinophils. The formation of a connective tissue capsule, necrosis of the helminth and the appearance of eosinophilic cell debris at the centre of the nodule indicated that the fibroblastic reaction assumed a chronic character. The cellular immune response developed more quickly and more strongly in immunized animals than in their nonimmunized counterparts. Granuloma formation takes place in a similar manner in the case of human infections. In the case of infection with Toxocara canis larvae, Gutierrez (1990) reported that the migrating larvae first became surrounded by an infiltrate containing eosinophils, histiocytes, lymphocytes, foreign-bodytype giant cells and polynucleated cells, and eventually the process led to the encapsulation of larvae.

The tissue reaction elicited by fish parasites was studied in detail by Reichenbach-Klinke (1954/55) who investigated the formation of 'parasite cysts' in the case of different parasite species. Taking Ichthyophonus hoferi as a prototype, he described in detail the formation of the connective tissue capsule surrounding the cysts. The histopathological aspects of the epithelioid cell reaction were studied in detail by Amlacher (1968). Investigating fish tuberculosis, he called attention to cell necroses occurring at the centre of the epithelioid cell aggregates. Histopathological works on fish contain few data on giant cell formation. However, Ferguson (1989) mentions that in processes associated with granuloma formation the appearance of

Figs. 12 to 15. Anguillicola crassus infecting Anguilla anguilla. Fig. 12. Cysts (c) containing serum and necrotic cells in the swimbladder mucosa of an eel infected by $A$. crassus. H\&E, $\times 36$. Fig. 13. Magnified detail of Fig. 13. The cyst lined with epithelium and filled with serum, located in the mucosa, contains degenerate cells (arrows) and fibrin threads. H\&E, $\times 100$. Fig. 14. Granuloma $(\mathrm{g}$ ) containing a 3rd stage A. crassus larva and cysts filled with inflammatory cells ( $\mathrm{p}$ ) and serum (s) on the intestinal serosa of eel. H\&E, $\times 40$. Fig. 15. Granuloma containing 3rd stage A. crassus larva (arrow) on the intestinal wall. The serosa has separated from the surface of the granuloma, and the space between the two is filled with serous exudate (s). H\&E, $\times 120$ 
epithelioid cells, macrophages and lymphocytes is sometimes accompanied by the formation of giant cells. These giant cells are usually of the foreign-body type; however, sometimes the fish organism is prone to the formation of Langhans-type giant cells as well.

There is a relative scarcity of data in the literature on the histopathology of anguillicolosis. Van Banning \& Haenen (1990) arrived at the conclusion that the inflammatory reaction and connective tissue proliferation observed in the swimbladder wall in anguillicolosis were primarily due to the adult helminths. They emphasized that fibrotic thickened swimbladders are not suitable for further invasion and survival of Anguillicola crassus. In their experimental study of larval migration, Haenen et al. (1989) observed haemorrhages and the accumulation of mononuclear phagocytes around some of the migrating larvae in the stomach wall but found neither inflammatory changes nor fibrosis in the swimbladder. At the same time, during a study of natural cases, Csaba et al. (1993) observed lymphocytes, macrophages and oedema around the larvae in the swimbladder wall, and even described the formation of larva-containing nodules the size of a pinhead in the intestinal wall. The granulation tissue present in those nodules also contained foreign-bodytype giant cells. Molnár et al. (1993) described the formation of granulation tissue around the larvae without going into the details of the process. That work also mentioned the formation of a granuloma consisting of eosinophilic cells around the 3rd stage larvae stuck in the intestine. The discrepancy between the observations of Haenen et al. (1989) and those of the 2 other research teams obviously results from the fact that while the former authors studied the results of a nonrecurrent infection, Csaba et al. (1993) and Molnár et al. (1993) recorded the outcome of an infection recurring several times. Eosinophilia does not seem to be as common in eels as in other fishes or mammals, as apart from the case described by Molnár et al. (1993) in the present work foci consisting of eosinophilic cells were not detected in the intestine. At the same time. the formation of giant cells within the granulomas seems to be much more common than was supposed by Molnár et al. (1995). Namely, in contrast to what was reported by the latter authors, giant cells may appear not only around 2 nd stage $A$. crassus larvae that abnormally get into the swimbladder wall, but around necrotic 3 rd and 4 th stage larvae as well. A further difference is that while the above authors reported only the presence of foreign-body-type giant cells, in the present work both foreign-body-type and Langhans-type giant cells were detectable among the epithelioid cells surrounding the larvae.

Responsible Subject Editor: W. Körting, Hannover, Germany
Acknowledgements. During the work of collecting, dissection and processing, the author received substantial help from his immediate colleagués. Csaba Székely, Ferenc Baska and Ms Enese Papp, which is gratefully acknowledged. The work was supported by the National Research Fund (OTKA), contract no. 1985.

\section{LITERATURE CITED}

Amlacher, E. (1968). Experimentelle Befunde zur Pathologie und Bakteriologie der Fischtuberkulose (ein Beitrag zur weiteren Klärung des 'Ichthyophonusproblem' bel Zierfischen. Z. Fisch. N.F. 16: 85-112

Csaba, Gy., Láng, M. Sályi, G., Ramotsa, J, Glávits, R., Rátz, F. (1993). The nematode Anguillicola crassus (Nematoda, Anguillicolidae) and its role in the death of eels in Lake Balaton during 1991. Magy. Állatorv. Lapja 48: 11-21

Frenkel, J. K., Taraschewski, H., Voigt, W. P. (1988). Important pathologic effects of parasitic infections of man. In: Mehlhorn, H. (ed.) Parasitology in focus. Springer-Verlag, Berlin, p. 538-590

Gutierrez, Y (1990). Toxocara - visceral larva migrans. In: Diagnostic pathology of parasitic infections with clinical correlations. Lea and Febiger, Philadelphia, p. 262-272

Ferguson, H. W. (1989). Systemic pathology of fish. lowa State University Press, Ames

Haenen, O. L. M., Grisez, L., De Charleroy, D., Belpaire, C., Ollevier, F. (1989). Experimentally induced infections of European eel Anguilla anguilla with Anguillicola crassus (Nematoda, Dracunculoidea) and subsequent migration of larvae. Dis. aquat. Org. 7: 94-101

Molnár, K. (1993). Effect of decreased oxygen content on eels (Anguilla anguilla) infected by Anguillicola crassus ( $\mathrm{Ne}$ matoda: Dracunculoidea). Acta Vet. Hung. 41: 349-360

Molnár, K., Baska, F., Csaba, Gy., Glâvits, R., Székely, Cs. (1993). Pathological and histopathological studies of the swimbladder of eels Anguilla anguilla infected by Anguillicola crassus (Nematoda: Dracunculoidea). Dis. aquat. Org. 15: $41-50$

Molnár, K., Szakolczai, J., Vetési, F. (1995). Histological changes in the swimbladder wall of eels due to abnormal location of adults and second stage larvae of Anguillicola crassus. Acta Vet. Hung. 43: 125-137

Molnár, K., Székely, Cs., Baska, F. (1991). Mass mortality of eel in Lake Balaton due to Anguillicola crassus infection. Bull. Eur. Ass. Fish Patho]. 11. 211-212

Molnár, K. Székely, Cs., Perényi, M. (1994). Dynamics of Anguillicola crassus (Nematoda: Dracunculoidea) infection in eels of Lake Balaton, Hungary. Folia Parasitol. 41: 193-202

Poynter, D. (1966). Some tissue reactions to the nematode parasites of animals. In: Dawes, B. (ed.) Advances in parasitology 4. Academic Press, London, p. 321-383

Reichenbach-Klinke, H.-H. (1954/55). Untersuchungen über die bel Fischen durch Parasiten hervorgerufenen Zysten und deren Wirkung auf den Wirtskörper. Teil II. Z Fisch. 4: N.F. $1-52$

Székely, Cs. (1993). Paratenic hosts for the parasitic nematode Anguillicola crassus in Lake Balaton, Hungary. Dis. aquat. Org. 18: $11-20$

van Banning, P., Haenen, O. L. M. (1990). Effect of the swimbladder nematode Anguillicola crassus in wild and farmed eel, Anguilla anguilla. In: Perkins, F. O., Cheng, T. C. (eds.) Pathology in marne science. Academic Press, New York, p. 317-330

Manuscript first recelved: April 20, 1994

Revised version accepted: August 31, 1994 